\title{
Achieving sustainable buildings: the role of heating, ventilation and air-conditioning
}

\author{
Hassam Nasarullah Chaudhry* \\ School of Energy, Geoscience, Infrastructure and Society, Heriot-Watt University, 294345 Dubai, United Arab Emirates
}

Received: 6 April 2016 / Accepted: 5 May 2016

\begin{abstract}
With the ever-increasing population and global economy, the dependency on usage of nonrenewable resources of energy is cumulating in direct proportion. Nevertheless, the non-renewable potential of these resources is certainly a leading worldwide issue, and one, which has gained substantial international interest over the past decades. Large and attractive opportunities exist to reduce building's energy use at lower costs and higher returns than other sectors. At the same time, substantial investments will be required to achieve this target as outlined by the Paris Agreement. These will require the combination of social, economic and environmental actions, including building energy codes, investment subsidies, labelling and reporting mechanisms, increased and trained workforce capacity, and evolving energy-efficient designs and HVAC technologies.
\end{abstract}

Keywords: HVAC / Passive / Sustainable buildings / Ventilation

The Paris Agreement on December 12th, 2015 marked the latest step in the evolution of the UN climate change regime, which originated in 1992 with the adoption of the Framework Convention. The United Nations Framework Convention on Climate Change (UNFCCC) established long-term objectives for reiterating the goals of limiting global temperature increase well below $2{ }^{\circ} \mathrm{C}$, while urging efforts to limit the increase to $1.5^{\circ} \mathrm{C}$ and extending the current goal of mobilising $\$ 100$ billion a year in support by 2020 through 2025 [1]. This agreement provides a significant opportunity for the building sector to encapsulate mass savings in the way we use energy, especially for heating, ventilation and air-conditioning (HVAC).

Building energy is part of a complex system that includes transport and urban planning and has major social consequences as well as climate change impacts. The energy mix is also important in determining carbon dioxide emissions. Buildings worldwide account for a surprisingly high $40 \%$ of global energy consumption, and the resulting carbon footprint, significantly exceeding those of all transportation combined. Energy consumption of the world is driven largely by residential use, with a major proportion of the electricity being consumed by the building sector $[2,3]$.

\footnotetext{
* e-mail: H.N.Chaudhry@hw.ac.uk
}

With the ever-increasing population and global economy, the dependency on usage of non-renewable resources of energy is cumulating in direct proportion. Nevertheless, the non-renewable potential of these resources is certainly a leading worldwide issue, and one, which has gained substantial international interest over the past decades. Large and attractive opportunities exist to reduce building's energy use at lower costs and higher returns than other sectors. At the same time, substantial investments will be required to achieve this target as outlined by the Paris Agreement. These will require the combination of social, economic and environmental actions, including building energy codes, investment subsidies, labelling and reporting mechanisms, increased and trained workforce capacity, and evolving energy-efficient designs and HVAC technologies.

Mechanical HVAC units are common solutions for providing effective and adequate fresh air requirements. Previous studies have shown that active systems with complex and integral mechanisms require a high level of energy input. Electricity usage of the active building cooling systems employed at present is sometimes substantially higher at relatively low cost of equipment, thereby making them financially appealing to the building sector. The energy consumption for typical air handling units can go up to $20,000 \mathrm{~W}$ while typical desiccant cooling systems can consume up to $55,000 \mathrm{~W}$ of power 


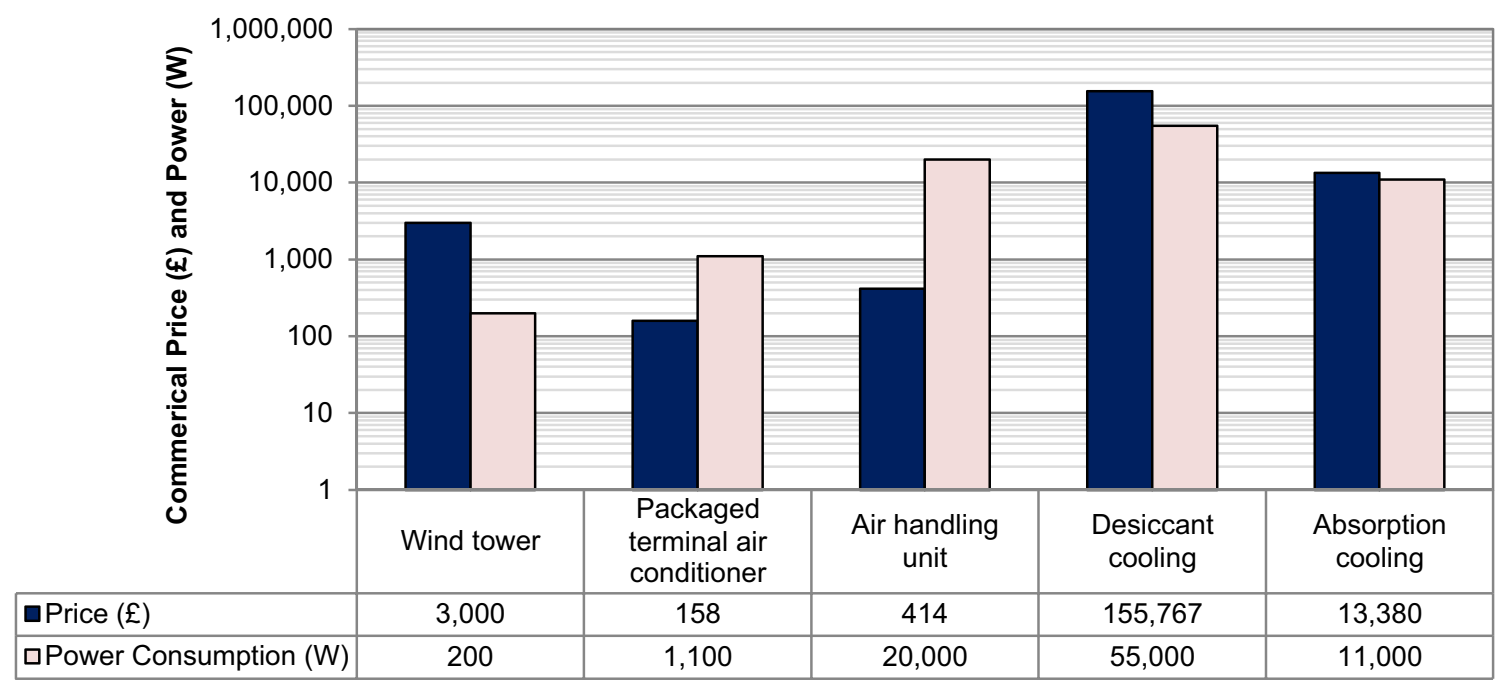

Fig. 1. Comparison of cost and power of building heating, ventilation and air-conditioning (HVAC) systems on the log scale [4].

$[4,5]$. Achieving the same level of ventilation and space conditioning using only natural resources (termed passive ventilation) would thus make a dramatic impact on the energy performance (Fig. 1).

Various strategies in buildings are already being practiced which exploit temperature and wind velocity parameters to reduce cooling loads in order to limit the expense for supplementary power consumption [6-8]. Since the residential and commercial building sectors consume a major load of the energy consumption, there is a significant opportunity for minimising the external electricity supply using passive cooling techniques. A characteristic feature of passive cooling involves the reduction of electricity usage by active air-conditioning or by minimising heat gains through natural ventilation. Natural ventilation refers to the fresh air supply from outdoor (macro-climate) to indoors (micro-climate) through non-mechanical methods and, if combined with a refrigerant-free heat transferring mechanism, can contribute in reducing the carbon footprint of new and existing dwellings.

Extensive studies conducted by Chaudhry and Hughes [9-11] have emphasised on the benefits of incorporating natural phase change materials such as water within the building ventilation systems in order to reduce the overall energy load. Combining passive heat transfer technologies such as heat pipes with natural ventilation is the way forward to achieve sustainable buildings. The scientific advancement of research into the application of passive HVAC mechanisms for effective heat transport is gradually increasing through the use of advanced Computational Fluid Dynamics (CFD) codes and complex experimentation techniques. The outcomes from this proof-of-concept study displayed a passive airside temperature reduction of up to $4{ }^{\circ} \mathrm{C}$ for an external air velocity of $1 \mathrm{~m} / \mathrm{s}$. The mean overall effectiveness of the heat pipe heat exchange medium was calculated at $6.4 \%$, achieving a cooling capacity of $976 \mathrm{~W}$ when the outdoor wind speed was increased to $2.3 \mathrm{~m} / \mathrm{s}$ (Fig. 2).
Natural ventilation mechanisms such as wind towers are now increasingly being employed in new buildings to reduce the energy consumption and resulting carbon footprint and these are underlined in the studies conducted by Calautit et al. [12,13]. The integration of natural ventilation wind catchers as a low energy alternative to mechanical HVAC system or as a support to it (i.e. hybrid system) has demonstrated the potential to improve the Indoor Air Quality (IAQ) and reduce carbon emissions by reducing reliance on energy-intensive HVAC. The results have indicated a cooling potential of up to $12{ }^{\circ} \mathrm{C}$ under the hot air climatic conditions in the Middle East [14].

As an Associate Editor of Sustainable Buildings, I look forward to receiving your scholarly contributions on increasing knowledge and awareness in the field of sustainable buildings and HVAC. I welcome scientific research demonstrating basic concepts associated with sustainable buildings and the role of HVAC for ensuring high performance buildings in their design and operation phase. Sustainable Buildings will publish original, interdisciplinary research articles, comprehensive reviews and short communications that demonstrate the work being conducted and developed by institutions and organisations from around the world. Articles on policies, problem identification and formulation and case studies on all aspects of buildings will also be given full consideration.

\section{References}

1. 21st Session of the Conference of the Parties to the United Nations Framework Convention on Climate Change (COP 21), November 30-December 12, 2015 (2015)

2. Energy Efficiency in Buildings, World Business Council for Sustainable Development (Switzerland, Atar Roto Presse SA, 2009) 

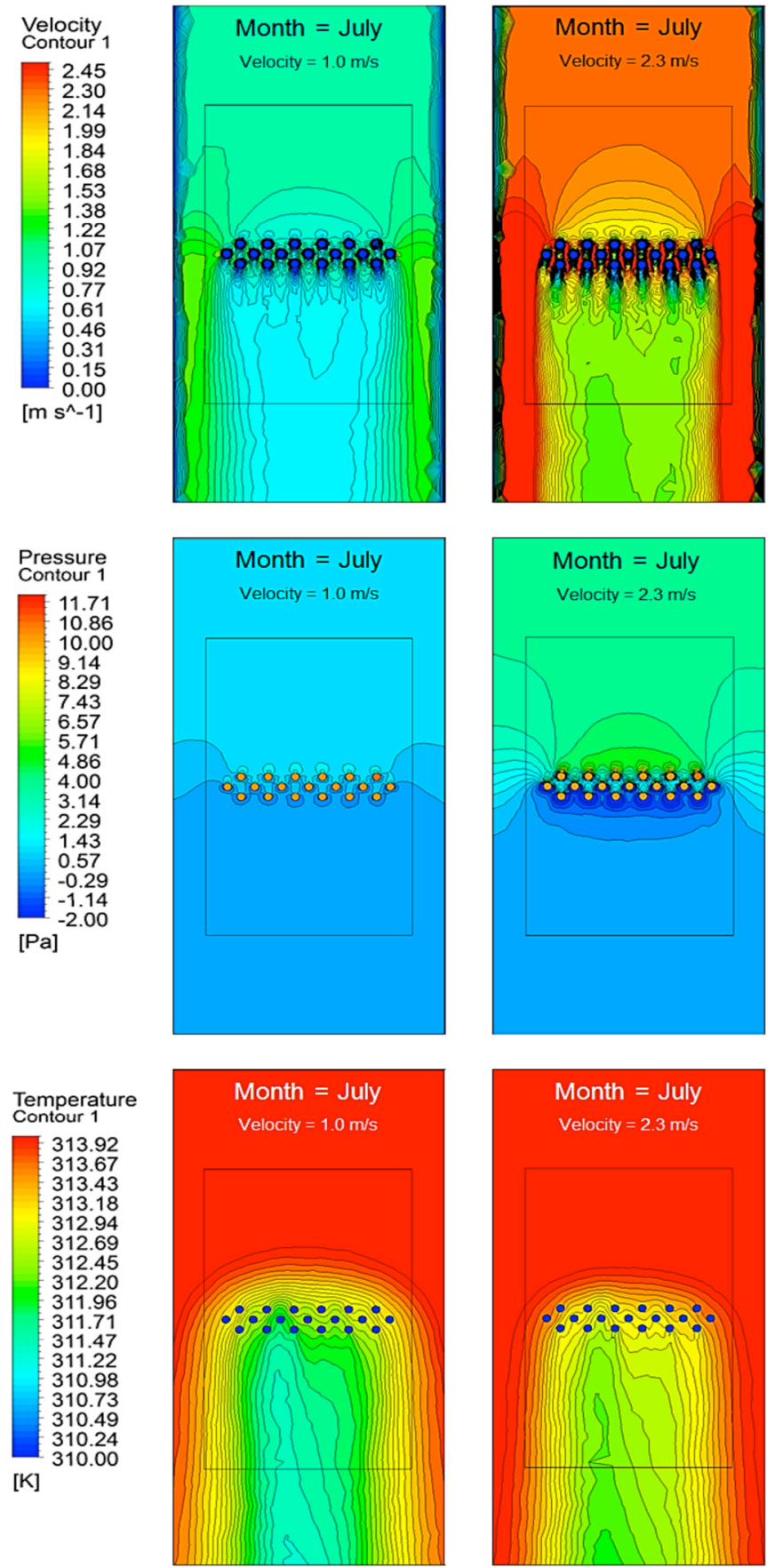

Fig. 2. Heat pipes used as a passive pre-cooling medium for reducing building air-conditioning loads in hot climates [10].
3. Living Planet Report, World Wide Fund for Nature (Gland, Switzerland, WWF International, 2012)

4. B.R. Hughes, H.N. Chaudhry, S.A. Ghani, A review of sustainable cooling technologies in buildings, Renew. Sustain. Energy Rev. 15, 3112 (2011)

5. H.N. Chaudhry, B.R. Hughes, S.A. Ghani, A review of heat pipe systems for heat recovery and renewable energy applications, Renew. Sustain. Energy Rev. 16, 2249 (2012)

6. H.N. Chaudhry, J.K. Calautit, B.R. Hughes, Computational analysis of a wind tower assisted passive cooling technology for the built environment, J. Build. Eng. 1, 63 (2015)

7. H.N. Chaudhry, B.R. Hughes, Analysis of the thermal cooling capacity of heat pipes under a low Reynolds number flow, Appl. Therm. Eng. 71, 559 (2014)

8. H. Awbi, Basic concepts for natural ventilation of buildings, in CIBSE BSG Seminar: Natural and Mixed-Mode Ventilation Modelling, University of Reading, 2010

9. H.N. Chaudhry, B.R. Hughes, Climate responsive behaviour of heat pipe technology for enhanced passive airside cooling, Appl. Energy 136, 32 (2014)

10. H.N. Chaudhry, B.R. Hughes, Passive pre-cooling potential for reducing building air-conditioning loads in hot climates, HVAC\&R Res. 20, 738 (2014)

11. H.N. Chaudhry, A study on optimising heat pipe geometrical parameters for sustainable passive cooling within the built environment, Appl. Therm. Eng. 93, 486 (2016)

12. J.K. Calautit, B.R. Hughes, H.N. Chaudhry, S.A. Ghani, CFD analysis of a heat transfer device integrated wind tower system for hot and dry climate, Appl. Energy 112, $576(2013)$

13. J.K. Calautit, H.N. Chaudhry, B.R. Hughes, S.A. Ghani, Comparison between evaporative cooling and a heat pipe assisted thermal loop for a commercial wind tower in hot and dry climatic conditions, Appl. Energy 101, 740 (2013)

14. J.K. Calautit, B.R. Hughes, A passive cooling wind catcher with heat pipe technology: CFD, wind tunnel and field-test analysis conditions, Appl. Energy 162, 460 (2016)

Cite this article as: Hassam Nasarullah Chaudhry, Achieving sustainable buildings: the role of heating, ventilation and airconditioning, Sust. Build. 1, 1 (2016) 